\title{
Optimizing the Migration to Future-Generation Passive Optical Networks (PON)
}

\author{
Marilet De Andrade, Massimo Tornatore, Sebastià Sallent, and Biswanath Mukherjee
}

\begin{abstract}
We study the upgrading problem of existing Passive Optical Networks (PONs) that need to increase their capacity at different points in time. Our method upgrades line rates and migrates network services over new wavelength channels based on increasing traffic demand and cost constraints. Our method minimizes capital expenses and system disruptions, while ensuring effective resource usage. Our multistep model uses Mixed Integer Linear Program (MILP) formulations whose cost parameters are set by a pricing policy. We evaluate the PON upgrade through installation of single-wavelength transceivers or multiple-wavelength arrays of transceivers. We consider a typical case study, which is solved using CPLEX. Illustrative examples demonstrate the attractive properties of our method.
\end{abstract}

Index Terms-Access network, capacity upgrade, mixed integer linear program, passive optical network, traffic growth.

\section{INTRODUCTION}

D ATA networks are experiencing sustained traffic growth. Demands of emerging applications will exceed today's access network capacity. Multiplayer games, e-health, e-learning, e-culture based on 3-D full-HD (High-Definition) video, etc. are examples of bandwidth-hungry applications and services. Passive Optical Network (PON) is an excellent choice of access network in terms of offered capacity and cost.

PON is a point-to-multipoint access network with typically a logical tree topology. The terminal equipment at the trunk of the tree is called Optical Line Terminal (OLT) and typically resides at the Service Provider's (SP) facility. The OLT is connected to a passive optical splitter (also called remote node) using an optical trunk fiber, that fans out at the splitter to multiple optical drop fibers to which Optical Network Units (ONUs) are connected [1]. Since the signal path from OLT to ONUs uses passive elements, operational expenditures (OpEx) due to maintenance, energy supply, and cooling at the remote node are not involved. Typical distances covered are 10-20 km. Legacy PONs employ two wavelength channels: an upstream channel (from

Manuscript received March 08, 2010; revised July 06, 2010; accepted July 06, 2010. Date of current version November 24, 2010. The work of M. De Andrade, M. Tornatore, and S. Sallent was performed while they were with the University of California-Davis. This work was supported in part by the US National Science Foundation Grant CNS-0832176. The work of M. De Andrade and S. Sallent were supported in part by the Spanish Ministry of Education within the framework of projects TEC2009-13901-C02-01 and PR2009-0464.

M. De Andrade is with Universitat Politècnica de Catalunya, Castelldefels 08860 Spain (e-mail: marilet@entel.upc.edu).

M. Tornatore is with Politecnico di Milano, Milano, 20133 Italy (e-mail: tornator@elet.polimi.it).

S. Sallent is with Universitat Politècnica de Catalunya, Castelldefels 08860 Spain (e-mail: sallent@entel.upc.edu).

B. Mukherjee is with the University of California, Davis, CA 95616 USA (email: mukherje@cs.ucdavis.edu).

Digital Object Identifier 10.1109/JSYST.2010.2082190
ONUs to OLT shared in time domain) and a downstream broadcast channel (from OLT to ONUs) [2].

Due to expected increase in traffic demands, recent efforts have focused on upgrading the line-rate of current PON's (1 or $2.5 \mathrm{Gbps}$ ) to $10 \mathrm{Gbps}$, while keeping backward compatibility with legacy services [3]-[6]. Besides line-rate upgrades, WDMbased (Wavelength Division Multiplexing) PON architectures are being considered as an option for the ITU Next-Generation PON standard [7]. In such architectures, new wavelengths can be added to the PON in order to increase its capacity [8]-[10]. However, since in most cases, a dedicated wavelength is allocated to each ONU, the network cannot exploit statistical multiplexing to achieve efficient capacity usage. In these architectures [11], the passive optical splitter is typically substituted by an AWG (Array Waveguide Grating). Unfortunately, this procedure implies a major disruption to the network (since the remote node is connected to all the ONUs and OLT), while as studied in [6] and [12], smooth and cost-effective migration is crucial in PON evolution; and two requirements for Next-Generation PON are coexistence with the already-deployed Legacy PON, and minimization of service disruption for subscribers who are not migrating [13].

An important option to guarantee coexistence and also use WDM to add new wavelengths is to implement TDM-WDM (Time Division Multiplexing-WDM) hybrid PON [14], where ONUs may support and share more than one wavelength, each of which can be shared in time among different users using TDM. In TDM-WDM hybrid PON, the passive optical splitter does not need to be replaced by an AWG. Therefore, new wavelength channels can be added on an as-needed fashion to support ONUs that require extra capacity, by changing only the end-devices that need an upgrade.

Algorithms have been proposed to dynamically allocate wavelength and bandwidth to each ONU [15], [16]. However, to the best of our knowledge, no work has been done to optimally calculate how many wavelengths should be added, when to add them, and at which line rate, in order to achieve a cost-effective and smooth PON evolution. Reference [17] uses multiple-period analysis to upgrade line rates in optical core networks. To our knowledge, our work is the first one that proposes a method for calculating optimal capacity upgrades in PONs based on traffic demands over multiple time periods. Our method is based on a multistep cost-and-network-upgrade model based on Mixed Integer Linear Program (MILP) formulations and pricing policies. This model allows user-by-user upgrade according to their traffic demands, while minimizing the number of disruptions to only the elements being upgraded through a new wavelength or line rate. 
The rest of the paper is organized as follows. In Section II, we formulate the MILP problem with pricing policies and we introduce our multistep PON-capacity migration method. Section III describes a case study and the parameters used for testing the proposed method. In Section IV, we present results of the tests performed over the example network scenario, and we compare the results with that of two other PON upgrading approaches. Section V concludes the paper.

\section{A METHOD to Optimize PON UPGRADE PROCESS}

Our method calculates optimal capacity upgrades for PONs using MILP formulations and appropriate pricing policies. It can be adapted to the specific requirements of an SP whose PON needs to be upgraded, by tuning parameters to the SP's specific network values. Although our analysis can be applied either to downstream or upstream channels, throughout the rest of the paper, we assume to be working with upstream channels.

Our general problem scenario is a PON that can evolve through line-rate upgrades and/or addition of new wavelength channels. Our analysis considers a number of possible line rates for the PON and insertion of new wavelengths in the system by adding either single-wavelength transceivers at a time or multiple-fixed-wavelength arrays of transceivers.

\section{A. MILP Problem Formulation}

To choose the optimal solution over all possible upgrade options for a PON towards a TDM-WDM hybrid PON, we propose the MILP formulation below. In our method, the following MILP will be run over multiple periods of time which will be inter-related by using some constants that depend on the network status during the previous periods.

Variables:

$l_{k, i, j} \quad$ binary variable that is 1 if the $i$ th ONU is operating on wavelength $j$ with rate $k$; note that an ONU, in order to support an additional wavelength $j$, needs to be equipped with an additional transceiver;

$c_{k, j} \quad$ binary variable that is 1 if the $j$ th wavelength is operative on rate $k$;

$\beta_{i, j} \quad$ binary variable that is 1 if the $i$ th ONU has any traffic over wavelength $j$;

$b w_{i, j} \quad$ integer variable that represents the bandwidth in Mbps that ONU $i$ has over wavelength $j$;

$U_{\max } \quad$ integer variable that represents the maximum bandwidth occupation over all the wavelengths.

\section{Constants:}

$K \quad$ set of line rates supported by the PON;

$N \quad$ set of ONUs existing in the PON;

$L \quad$ set of wavelengths that can be used in the PON;

$\alpha \quad$ cost per unit of bandwidth to support load balancing over all wavelengths;

$R_{k} \quad$ value in Mbps of the $k$ th line rate;
$M \quad$ value used to obtain a binary number out of an integer, and accomplishes: $M \gg b w_{i, j}$;

$F_{i} \quad$ maximum number of wavelength channels that ONU $i$ can support.

Constants for Multiple Periods: The following constants will change with every period in which we apply the MILP, in order to calculate how a PON evolves. These constants will link one period to the other.

$W_{k, j}$ cost to support wavelength $j$ with rate $k$ at the OLT;

$Z_{k, i, j}$ cost to support wavelength $j$ with rate $k$ at $\mathrm{ONU} i$;

$\Omega_{j} \quad$ previous line-rate value of $j$ th wavelength before running the MILP;

$B_{i} \quad$ guaranteed bandwidth for ONU $i$;

$E_{i} \quad$ set of wavelengths that have not been allocated to ONU $i$ in any previous step;

$F_{i, o} \quad$ number of wavelength channels that ONU $i$ previously supported.

Objective:

$\min \left(\sum_{k=1}^{K} \sum_{i=1}^{N} \sum_{j=1}^{L} Z_{k, i, j} l_{k, i, j}\right.$

$$
\left.+\sum_{k=1}^{K} \sum_{j=1}^{L} W_{k, j} c_{k, j}+\alpha U_{\max }\right) .
$$

Subject to:

$$
\begin{aligned}
& \sum_{k=1}^{K} R_{k} c_{k, j} \geq \sum_{i=1}^{N} b w_{i, j} \quad \forall j \in L \\
& \sum_{k=1}^{K} R_{k} c_{k, j} \geq \Omega_{j} \quad \forall j \in L \\
& \sum_{j=1}^{L} b w_{i, j}=B_{i} \quad \forall i \in N \\
& \beta_{i, j} \geq \frac{b w_{i, j}}{M} \quad \forall i \in N, \forall j \in L \\
& \beta_{i, j} \leq b w_{i, j} \quad \forall i \in N, \quad \forall j \in L \\
& \sum_{j \in E_{i}} \beta_{i, j} \leq F_{i}-F_{i, o} \quad \forall i \in N \\
& \sum_{k=1}^{K} c_{k, j} \leq 1 \quad \forall j \in L \\
& \sum_{k=1}^{K} l_{k, i, j} \leq 1 \quad \forall i \in N, \quad \forall j \in L \\
& l_{k, i, j}=\left(c_{k, j}\right) \text { AND }\left(\beta_{i, j}\right) \quad \forall k \in K, \\
& \quad \forall i \in N, \forall j \in L \\
& U_{\max } \geq \sum_{i=1}^{N} b w_{i, j} \quad \forall j \in L .
\end{aligned}
$$

Equation (1) is a triple-objective function. The first and second terms stand for the cost of supporting wavelength $j$ with 
line rate $k$ at the ONUs and at the OLT, respectively. Here, cost is the cost per added transceiver. The third term represents the maximum utilization among all wavelengths with lower priority (given by a small value $\alpha$ ). Thus, our objective is to minimize the cost of supporting a new wavelength at a given line rate by the ONUs, minimize the cost of supporting a new wavelength at a given rate by the OLT, and, with a small priority, minimize the maximum utilization among all wavelengths in the PON (which performs load balancing, where load is fractional capacity utilization). Note: cost here is associated to capital expenses to install transceivers at OLT and ONUs, but other cost may apply.

Equation (2) constrains the maximum amount of traffic that can be placed on each wavelength. Equation (3) restricts the possible line rate that a wavelength channel can take according to the value of the previous line rate: according to (3), a wavelength channel's line rate can only increase or remain the same. Equation (4) ensures that the bandwidth assigned to an ONU satisfies its guaranteed bandwidth requirements.

By using (5) and (6), we associate a binary variable $\beta_{i, j}$ to the integer variable $b w_{i j}$ introducing a "big M" inequality. Equation (7) limits the number of channels that an ONU can use to support the traffic (note that second term of (7) accounts both the number of existing transceivers $F_{i o}$ and the newly enabled transceivers $F_{i}$ ). Equations (8) and (9) discard the possibility of having two different line rates over the same wavelength.

There is a logical relation among all the binary variables $\left(l_{k, i, j}, c_{k, j}, \beta_{i, j}\right)$ enforced in (10), which implies that ONU $i$ can only operate over wavelength $j$ with rate $k$ if that wavelength has rate $k$, and that ONU has traffic flowing over wavelength $j$. Note that even AND operator in (10) is not, rigorously speaking, a linear constraint, however logical operators among binary variables can be easily linearized [18]. Finally, in (11), variable $U_{\max }$ takes the value of maximum traffic occupation among all wavelength channels.

So far, the problem formulation suits a PON that has to plan addition of new channels via single-wavelength transceivers. If we have to add several wavelengths at a time (e.g., multiple fixed-wavelength array of transceivers), our formulation can be easily extended by including the following equation:

$$
\begin{array}{ll}
c_{k, v}=c_{k, v+1}=c_{k, v+2}=\cdots=c_{k, v+\gamma-1} & \forall k \in K, \\
& \forall v \in G(n)
\end{array}
$$

where $\gamma$ is the number of fixed wavelengths in the transceiver array, $v$ is the first wavelength of the group of wavelengths in any array, and $G(n)$ is set of wavelengths pertaining to group $n$ of an array of $\gamma$ transceivers. Equation (12) states that, once a wavelength from a group of wavelengths included in a $\gamma$-fixedwavelength array of transceivers is allocated in the system, the other wavelengths in that group are automatically supported.

By solving this MILP, we minimize cost and, secondarily, balance traffic in a PON; also, we obtain the traffic allocation over different wavelengths and the capacity upgrade needed to support the traffic at a particular point in time. But we are dealing with a multistep approach that considers the evolution of PON's capacity and bandwidth allocation over multiple periods of time. Below, we show how this single-period formulation (basic step) can be extended to calculate how a PON evolves over multiple periods of time.

\section{B. Capacity Upgrade Over Multiple Periods}

Over time, a PON will experience growth in traffic and it must respond accordingly. The best way to deal with the problem would be by reducing the number of disruptions or service cuts for the users. Thus, we consider very few changes that would lead to a disruption. So, we propose a multistep method to optimize network capacity upgrade, minimizing service disruptions and cost. We define the end of a period as the point of completion of a round of time when we will calculate the upgrades needed in the PON, e.g., the period could be a year. (In general, the period durations need not to be constant.) The SP may choose the most-suitable duration for its network. Below, we explain, step by step, our method sequence to be applied to all periods.

For current period $\tau$, do:

Step 1: Input New Traffic Demands: Before a period starts, obtain the traffic forecast or expected traffic demand at the end of the period, and determine the guaranteed bandwidth for all ONUs (constant $B_{i}$ for ONU $i$ ). ${ }^{1}$

Step 2: Collect Historical Data: Our upgrade calculations must consider existing resources available at every ONU and OLT at each period. Without this information, each period would be solved independently of previous changes (e.g., after more than two periods, an ONU's traffic may be totally transferred to a new wavelength, and we may lose information on the previous supported wavelength). By considering historical data, optimal solution for a new period can be obtained, by distributing the ONU's bandwidth over new and old wavelengths. By keeping track of prior changes, we exploit previously-supported wavelengths to optimally allocate traffic in the PON.

Step 3: Apply Pricing Policies: The cost of adding a wavelength and/or changing the line rate of a channel is not the same at every period and every device (OLT/ONU) in the network. A smaller cost should apply to a specific device if it is already supporting the wavelength channel at a given line rate. For this reason, Step 2 (collecting historical data) is essential to achieve a proper cost assignment. On the other hand, a larger cost should be assigned when upgrading a wavelength's line rate.

Pricing policies are used to calculate the cost parameters $W_{k, j}$ and $Z_{k, i, j}$ in the cost function which are updated at each step and depend on prior wavelength and line-rate allocations. $W_{k, j}$ is related to cost at OLT, and its value depends on changes at the previous period $(\tau-1) \cdot Z_{k, i, j}$ is related to the cost at the ONU. Calculation of $Z_{k, i, j}$ should depend on the history of supported wavelengths over previous periods, such that we do not pay again for an existing service. Pricing policies assure previous-investment and existing-resources awareness for each ONU and at the OLT. In the next subsection, we provide a detailed description of our proposed pricing policies.

Step 4: Run MILP: Finally, we solve the MILP, and obtain the bandwidth and wavelength channel allocations per ONU for period $\tau$.

\footnotetext{
${ }^{1}$ A possible extension of this work is to devise a traffic growth model and tie the upgrade mechanism to some traffic growth parameters, but this is beyond the scope of the present work
} 


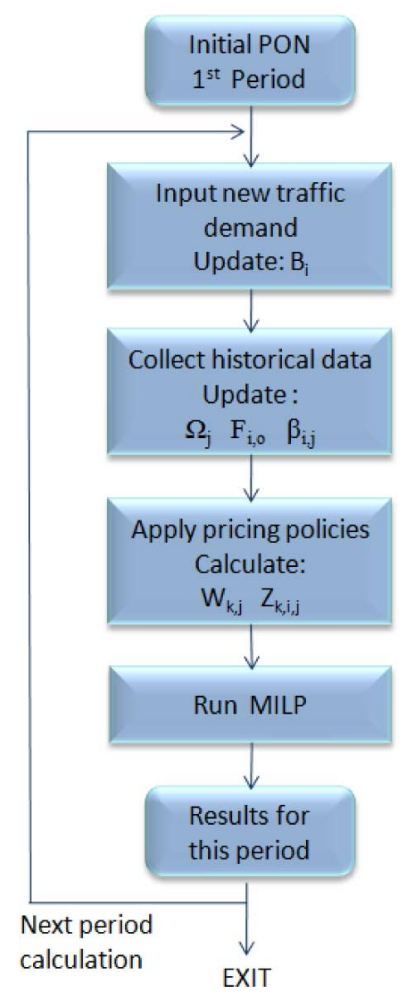

Fig. 1. Flow chart of the proposed PON upgrade method.

The flow chart in Fig. 1 summarizes the above steps. Here we can see the relation among bandwidth input and cost parameters with the MILP calculation. Note that some constants or parameters for multiple periods (see Section II-A) are updated at their corresponding step.

\section{Pricing Policies}

We provide examples of pricing policies that may be used to set the cost values in the objective function of our MILP. The MILP can choose the best combination of costs that suits the objective function and fulfill all traffic demands. The following three pricing policies are examples of how we can model cost of transceivers and line interfaces in the PON. First, we propose a base case that allocates a specific cost to add/modify transceivers at the ONUs or OLT. Second, we propose a policy to properly allocate a cost when we upgrade the network using transceiver arrays. Third, we study a similar approach to the first policy which makes use of more complete historical information. We consider that our PONs can support two different line rates, namely $R_{1}$ to $R_{2}$, on wavelength $j$, where $R_{2}>R_{1}$. In the following pricing policies, we assume that the system has been correctly set up with proper WDM filters at an early stage [12]. Hence, we do not consider the cost of adding filters into our pricing policies. Policies can be fine-tuned by the SP based on price trends and new devices.

Pricing Policy 1: Single-Wavelength Transceivers: Our Base Case is a simple policy to calculate $W_{k, j}$ and $Z_{k, i, j}$. To calculate $W_{k, j}$, we consider three cases to assign appropriate cost to implement the rates $R_{1}$ or $R_{2}:(i)$ if the previous line rate of wavelength $j$ is zero (i.e., $j$ is inactive), we assign cost values $W_{1, j}$ and $W_{2, j}$ to activate $j$ for the first time $\left(C_{1}\right.$ and $C_{2}$, respectively, with $C_{1}<C_{2}$ ) at any of the available line rates, (ii) if wavelength $j$ was active at line rate $R_{1}$, we assign a small value $\varepsilon$ to $W_{1, j}$ (because $R_{1}$ is already active and a new investment is not required to keep $R_{1}$ ), and $W_{2, j}$ gets the cost value that is required to upgrade the line rate $C_{2}+\omega$ ( $\omega$ is extra cost to perform the line-rate change, for example we assume $\omega=0.5$ ), and (iii) if wavelength $j$ was active at line rate $R_{2}$, it is not desirable to go back to a lower rate $\left(R_{1}\right)$, hence $W_{1, j}$ gets a very high value (e.g., $10^{6}$ ), and $W_{2, j}$ gets $\varepsilon$ (because it is already implemented and requires no new investment). Since prices for transceivers and line interfaces at ONUs are similar to those at OLT, we use $W_{k, j}$ to calculate ONU's cost. Now, $Z_{k, i, j}$ objective is to adapt the value of $W_{k, j}$ to ONU case.

To calculate $Z_{k, i, j}$, we first evaluate if ONU $i$ was already supporting wavelength $j$ in any previous period. If so, the cost will be $\delta * W_{k, j}$, where $\delta$ takes a small value. Otherwise, if ONU $i$ never supported wavelength $j$ before, then the cost will be $1^{*}$ $W_{k, j}$. (i.e., we assume that an ONU's cost take the same cost values as those given to the new OLT's transceivers).

$W_{k, j}=\varepsilon$ means that wavelength $j$ is already supported in the system, and $Z_{k, i, j}$ will take the same low value (due to $Z_{k, i, j}=$ $1 * W_{k, j}$ ) even if ONU $i$ was not supporting such wavelength. Thus, if a capacity upgrade is required for ONU $i$, this case leads or encourages our MILP to choose wavelength $j$. Given that the number of disruptions is proportional to cost, we set a low price to the situation that leads to lower disruption.

Pricing Policy 2: Multiple-Wavelength Arrays of Transceivers: To support multiwavelength transceiver arrays, we modify the pricing policy. Let group $n$ be a set of wavelengths supported by a transceiver array. Let the PON be able to support a number of wavelength groups. In our approach, a PON will first support group 1, until more capacity, i.e., more wavelengths, is needed. Then, we proceed to add wavelength group 2 to the system. After running out of capacity with the previous two groups, we can add wavelength group 3, and so on.

Thus, we calculate a new $W_{k, j}$ that conveys the historical data regarding which wavelength groups have been already supported in the PON. For a particular wavelength $j$ pertaining to group $n$, we calculate $W_{k, j}$ by evaluating four conditions: i) if all previous groups (smaller than $n$ ) have been supported by the PON, and group $n$ is not active, we assign cost values $W_{1, j}$ and $W_{2, j}$ of $C_{1}$ and $C_{2}$, respectively; ii) if there are wavelength groups with index lower than $n$, that are not supported by the PON, then the cost would be a high value (e.g., 1000) to give priority to a lower-than- $n$ group; iii) if group $n$ is being supported by the PON at line rate $R_{1}$, we assign the value of $\varepsilon$ to $W_{1, j}$, and a value of $C_{2}+\omega$ to $W_{2, j}$; and iv) if group $n$ is being supported by the PON at line rate $R_{2}, W_{1, j}$ gets a very high value $\left(10^{6}\right)$, and $W_{2, j}$ gets the value of $\varepsilon$.

To calculate $Z_{k, i, j}$, we first evaluate if ONU $i$ was already supporting wavelength $j$ in previous periods. If so, the cost will be $\delta * W_{k, j}$. Otherwise, if ONU $i$ never supported wavelength $j$ before, then the cost will be $C_{2} * W_{k, j}$ (due to the higher cost required to implement the new type of transceiver compared to single-wavelength-transceiver's).

Pricing Policy 3: Adding Line-Rate History (LRH) to the Calculation of $Z_{k, i, j}$ : Note that, in Policy $1, Z_{k, i, j}$ is calculated based on historical values of $\beta_{i, j}$, which contains information 
on the wavelengths that ONU $i$ supports. But no information is given to Policy 1 about which line rate was supported by ONU $i$ on its wavelengths, e.g., if ONU 1 supports wavelength 3 at 1 Gbps, the cost increases if we want to perform a line-rate upgrade (e.g., to $10 \mathrm{Gbps}$ ) over wavelength 3 . So, an alternate pricing policy to calculate the cost parameter at the ONU can be based on the use of line-rate history as well. A solution could be to use the historical values of variable $l_{k, i, j}$, that tells if a wavelength $j$ at rate $k$ has been supported by ONU $i$.

To calculate $Z_{k, i, j}$, we check if ONU $i$ supported wavelength $j$ at line rate $k$ in any previous period. If so, cost will be $\delta * W_{k, j}$; otherwise, $Z_{1, i, j}$ and $Z_{2, i, j}$ will be $C_{1}$ and $C_{2}$, respectively.

This pricing policy can be also added to the ONU's cost calculation in Policy 2. In the rest of the paper, we will refer to Policy 3 as adding Line-Rate History (LRH).

\section{CASE Study}

To test our method, we consider a practical case as follows. The PON serves a residential area with several buildings (say ten) and some houses (say six), so this PON has 16 ONUs and one OLT. Initial average load for a building (multi-dwelling unit) is $600 \mathrm{Mbps}$, and for a house, it is $100 \mathrm{Mbps}$. At this point, the PON has moved already from 1-Gbps line rate to 10 Gbps over the first wavelength $\left(\lambda_{1}\right)$. We refer to $\lambda_{1}$ as the legacy wavelength channel. Here, we only consider traffic load growth and upgrades over upstream channels.

Our model assumes a traffic growth factor of 1.5, i.e., traffic demands grow $50 \%$ every period (say a year) [17]. Real forecast of traffic growth may also be used by a SP. As traffic demands increase, we may add wavelengths with two possible line rates: $10 \mathrm{Gbps}$ and $40 \mathrm{Gbps}$. However, our method could also be applied to currently-deployed PONs using line rates of $1 \mathrm{Gbps} / 2.5$ Gbps, moving to $10 \mathrm{Gbps}$, with minor changes.

Due to difficulties to estimate the absolute cost of emerging components, we assume relative cost values. We consider that all costs in our case study will be relative to a reference cost, which is the cost required to upgrade an ONU to support a new wavelength at $10 \mathrm{Gbps}$. Then, by multiplying the reference cost to the relative costs presented in this case study, it is possible to obtain the total upgrading cost. For this reason, cost $C_{1}$ is set to 1 , which corresponds to the cost of adding a new wavelength at $10 \mathrm{Gbps}$ to any ONU. Now, the relative cost to add a new wavelength at $40 \mathrm{Gbps}\left(C_{2}\right)$ can be set to 2.5 instead of 4 , if we want to apply volume discount.

We test all pricing policies in Section II.C, evaluating the addition of single-wavelength transceivers, and 4-fixed-wavelength array of transceivers.

ONUs 11 to 16 have a wavelength limit $\left(F_{i}\right)$ of one to force the system to keep some users in the legacy channel. But the rest of the ONUs have $F_{i}=8$. This is favorable for users with low traffic that are not expected to grow drastically. We set the parameters to be 0.1 for $\varepsilon$ and $\delta, 0.5$ for $\omega$, and $10^{-6}$ for $\alpha$.

Next, we calculate the traffic growth forecast for the first pe$\operatorname{riod} \tau=1$. The initial wavelength allocation information is used as historical data. For example, at $\tau=1$, all ONUs support the legacy wavelength $\left(\lambda_{1}\right)$ at $10 \mathrm{Gbps}$. Then, we update
TABLE I

Wavelength Allocation Per ONU and Period, Base Case

\begin{tabular}{|c|c|c|c|c|c|c|}
\hline & $\begin{array}{c}\text { Period } \\
1\end{array}$ & $\begin{array}{c}\text { Period } \\
2\end{array}$ & $\begin{array}{c}\text { Period } \\
3\end{array}$ & $\begin{array}{c}\text { Period } \\
4\end{array}$ & $\begin{array}{c}\text { Period } \\
5\end{array}$ & $\begin{array}{c}\text { Period } \\
6\end{array}$ \\
\hline ONU 1 & $\lambda_{1}{ }^{\mathrm{a}}$ & $\lambda_{1}$ & $\lambda_{3}$ & $\lambda_{3}$ & $\lambda_{3}$ & $\lambda_{3}$ \\
\hline ONU 2 & $\lambda_{1}$ & $\lambda_{1}$ & $\lambda_{1} \lambda_{2}$ & $\lambda_{2}$ & $\lambda_{2}$ & $\lambda_{2}$ \\
\hline ONU 3 & $\lambda_{1}$ & $\lambda_{1}$ & $\lambda_{1}$ & $\lambda_{1}$ & $\lambda_{1}$ & $\lambda_{5}$ \\
\hline ONU 4 & $\lambda_{1}$ & $\lambda_{1}$ & $\lambda_{1}$ & $\lambda_{4}$ & $\lambda_{4}$ & $\lambda_{3} \lambda_{4}$ \\
\hline ONU 5 & $\lambda_{1}$ & $\lambda_{2}$ & $\lambda_{2}$ & $\lambda_{2}$ & $\lambda_{2}$ & $\lambda_{2}$ \\
\hline ONU 6 & $\lambda_{1}$ & $\lambda_{1}$ & $\lambda_{1}$ & $\lambda_{4}$ & $\lambda_{4}$ & $\lambda_{1} \lambda_{4}$ \\
\hline ONU 7 & $\lambda_{1}$ & $\lambda_{2}$ & $\lambda_{2}$ & $\lambda_{1}$ & $\lambda_{2}$ & $\lambda_{2}$ \\
\hline ONU 8 & $\lambda_{1}$ & $\lambda_{2}$ & $\lambda_{2}$ & $\lambda_{3}$ & $\lambda_{2}$ & $\lambda_{2}$ \\
\hline ONU 9 & $\lambda_{1}$ & $\lambda_{2}$ & $\lambda_{2}$ & $\lambda_{2}$ & $\lambda_{2}$ & $\lambda_{2}$ \\
\hline ONU 10 & $\lambda_{1}$ & $\lambda_{1}$ & $\lambda_{3}$ & $\lambda_{3}$ & $\lambda_{3}$ & $\lambda_{2} \lambda_{3}$ \\
\hline $\begin{array}{l}\text { ONUs } 11 \\
\text { to } 16\end{array}$ & $\lambda_{1}$ & $\lambda_{1}$ & $\lambda_{1}$ & $\lambda_{1}$ & $\lambda_{1}$ & $\lambda_{1}$ \\
\hline
\end{tabular}

${ }^{\mathrm{a} N o t a t i o n: ~} \lambda_{j}$ represents wavelength channel $j$ allocated to the ONU. Bold red text means that $\mathrm{ONU}$ is supporting a new wavelength at $10 \mathrm{Gbps}$. Bold and shadowed text denotes line rate of $40 \mathrm{Gbps}$. Two different wavelengths together indicate that this ONU is sharing bandwidth among them.

$\Omega_{j}(0)$ and $\beta_{i, j}(0)$ for all $i$ and $j$, which are needed to apply the pricing policies. Finally, we solve the MILP using CPLEX.

After this first iteration, we apply the steps of the method for the next periods, which are six periods in our example.

Note that, although we are keeping constant the number of ONUs in this example, it is feasible to add new ONUs to the PON. Then, we would need to incorporate the new initial parameters to update the MILP model.

\section{RESULTS AND DISCUSSION}

\section{A. Evolution Analysis}

Base Case: Adding Single-Wavelength Transceivers: Our first set of results using Policy 1 (Section II.C) is shown in Table I (we call this policy Base Case or " $1 \times 1$ Tx"). For every ONU, we display the evolution of its transceiver assignment over the six periods. The legacy wavelength $\lambda_{1}$ is able to support traffic increments in the first period. After that, in every period a new wavelength channel is added (as in periods 2,3 , 4 , and 6), or the line rate of an existing wavelength is upgraded from $10 \mathrm{Gbps}$ to $40 \mathrm{Gbps}$ (as in period 5). Overall, we need five wavelength channels when we reach the sixth period. Table I shows the primary characteristics of our method, that is the gradual capacity upgrade, with incremental investments on an "as-needed" basis.

From Table I, we observe that the maximum number of wavelengths allowed per ONU is respected. ONUs 11-16 use only the legacy channel. For ONUs 1-10, maximum number of wavelengths allowed is eight, but most of them support two channels including the legacy $\lambda_{1}$. ONUs 1, 2, 3, 5, 6, 7, and 9 support two channels, while ONUs 4, 8, and 10 support three. Moreover, by using a limited number of wavelengths, we are also reducing the number of disruptions in the system.

Let us study Table I in more detail. In period 3, ONU 2 is sharing its traffic among $\lambda_{1}$ and $\lambda_{2}$. Traffic sharing is only possible in TDM-WDM hybrid PONs. Although only ONU 2 seems to be sharing its traffic over two wavelengths, this is just part of the design to accomplish capacity upgrade needs. A PON may 


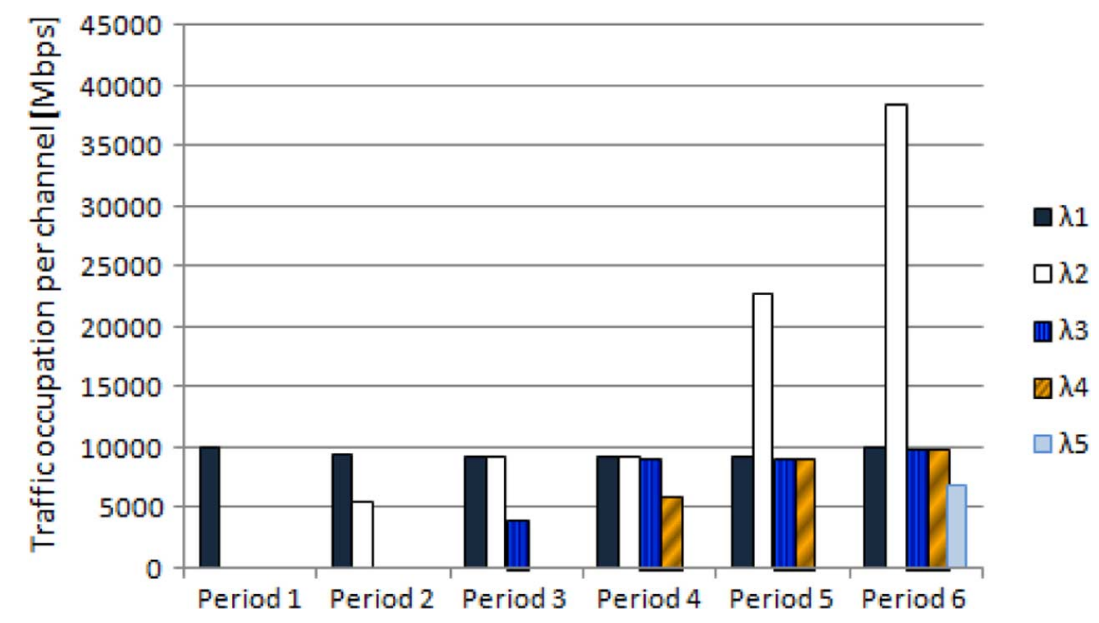

Fig. 2. Number of wavelengths assigned to the PON per period and its total traffic occupation in Mbps, for the Base Case (adding single-wavelength transceivers, with no line-rate history).

use a dynamic bandwidth allocation algorithm that simultaneously allocates the ONU's load over different supported wavelengths according to current load. TDM-WDM hybrid PONs can exploit statistical multiplexing to improve network performance and capacity usage.

Another property of our method is continuity in use of any ONU's wavelengths. For ONUs 1, 2, 3, 4, 5, 6, and 9, once a new wavelength is allocated, the ONU remains operating on that channel as long as possible to reduce disruptions.

Fig. 2 shows the occupation in Mbps of each wavelength per period. We summarize the evolution of our PON by noting the number of wavelengths being added in each period and observing the total traffic allocation per channel. Load balancing is a secondary objective of our MILP, and its priority is set by parameter $\alpha$, but we can observe that load balancing over the wavelength channels is applied in most cases. Note that in periods 5 and $6, \lambda_{2}$ exhibits a very high occupation compared to the rest of the wavelengths because it has been upgraded from 10 Gbps to 40 Gbps. Traffic occupation has similar levels for the rest of the wavelength channels, which is a result of load balancing (namely balancing the fractional channel utilization). Details on bandwidth and wavelength allocation per ONU and per period are shown in Table II (see " $1 \times 1$ Tx" fields).

Adding 4-Fixed-Wavelength Arrays of Transceivers: A new set of tests has been carried on adding arrays of transceivers (four wavelengths each) to the PON and using Policy 2 in Section II.C. We refer to this setup as ' $1 \times 4 \mathrm{Tx}$ '.

Table II (' $1 \times 4 \mathrm{Tx}$ ' case) shows wavelength and bandwidth allocation for all ONUs and at each period. Wavelength $\lambda_{1}$ remains a single transceiver in the initial setup. Once an ONU needs to be allocated with a new wavelength, it will automatically be equipped with an array of four transceivers. In Table III, case " $1 \times 4$ Tx," we can see more clearly when and which ONUs are getting such arrays of transceivers.

In period 2, there is an investment to equip four ONUs $(1,2,7$, and 8) with a 4-wavelength transceiver array. Period 2 onwards, these ONUs are supporting wavelengths: $\lambda_{2}, \lambda_{3}, \lambda_{4}$, and $\lambda_{5}$, besides the legacy wavelength. In period 3 , three more ONUs (3, 4 , and 9) start supporting wavelengths $\lambda_{2}$ to $\lambda_{5}$. ONU 10 gets a transceiver array in period 4 . The investment is distributed in time, according to needs.
Once an ONU is supporting a group of wavelengths (by means of an array of transceivers), the OLT can allocate bandwidth over one or more of the ONU's supported wavelengths. In Table II, we find that, for example, ONU 7 is placing its traffic over different wavelengths in different periods. It takes $\lambda_{3}$ in period 2, it changes to $\lambda_{5}$ in period 3, and then it uses $\lambda_{4}$ in periods 4 and 5 . Finally, in period 6 , ONU 7 shares the transmission of its traffic among three wavelengths $\left(\lambda_{1}, \lambda_{4}, \lambda_{5}\right)$. All these changes are happening at no extra cost, except for the initial investment in period 2. This type of transceiver adds more flexibility to the system and facilitates an optimal distribution of bandwidth since transmission over different wavelengths can be shared in time.

Installing transceiver arrays initially saves a number of single installations of devices (single transceivers) at ONUs. Few wavelengths supported by the system may be good enough to address the PON's traffic demands for some time, while exploiting the statistical multiplexing in the PON (i.e., TDM-WDM PON). This upgrade scheme is more convenient from the OpEx point of view: because the same 4-wavelength transceiver array is being installed in the ONUs, it is simpler to maintain a good inventory of similar spare devices.

All-in-One Period Analysis: An interesting comparison for our multistep approach is to consider a single-step optimization, in which our model in Section II is directly applied to the long-term traffic forecast (sixth period), and the network is equipped accordingly starting from the first period (i.e., consider a single period whose input traffic is the traffic from the sixth period). The historical data only contains the network state before the first period. Results are presented in Table II (see "All-in-one"). With this scheme, six wavelengths are needed, and the legacy wavelength changes its line rate from $10 \mathrm{Gbps}$ to 40 Gbps. All-in-one-period approach requires one wavelength more than the multiple-period Base Case, but the overall cost (expressed in terms of transceiver at both OLT and ONU sides) is less, since a single-step method leads to better optimization of capacity and traffic assignment. Nonetheless, we will see that, including depreciation, the expenses become significantly higher than the Base Case, since the equipment deployment has to be done once, and from the first moment. 
TABLE II

BANDWIDTH AND WAVELENGTH ALLOCATION DETAILS

\begin{tabular}{|c|c|c|c|c|c|c|c|}
\hline & $\begin{array}{c}\text { Cases with } \\
\text { WH }\end{array}$ & Period 1 & Period 2 & Period 3 & Period 4 & Period 5 & | Period 6 \\
\hline \multirow{3}{*}{ ONU 1} & $1 \times 1 \mathrm{Tx}$ & $900 @ \lambda 1$ & $1350 @ \lambda 1$ & 2025@入3 & 3038@入3 & 4556@入3 & $6834 @ \lambda 3$ \\
\hline & $1 \times 4 \mathrm{Tx}$ & $900 @ \lambda 1$ & $1350 @ \lambda 2$ & 2025@入4 & 3038@入4 & 4556@入 & 6834@入3 \\
\hline & All-in-one & - & - & - & - & - & 6834@ג1 \\
\hline \multirow{3}{*}{ ONU 2} & $1 \times 1 \mathrm{Tx}$ & $900 @ \lambda 1$ & $1350 @ \lambda 1$ & $\begin{array}{l}1011 @ \lambda 1 \\
1014 @ \lambda 2\end{array}$ & 3038@入2 & 4556@入2 & 6834@入2 \\
\hline & $1 \times 4 \mathrm{Tx}$ & $900 @ \lambda 1$ & $1350 @ \lambda 2$ & 2025@入4 & 3038@入2 & $4556 @ \lambda 5$ & 6834@入4 \\
\hline & All-in-one & - & 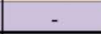 & - & - & 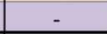 & 6834@ג1 \\
\hline \multirow{3}{*}{ ONU 3} & $\mathrm{x} 1 \mathrm{Tx}$ & $900 @ \lambda 1$ & $1350 @ \lambda 1$ & 2025@入1 & 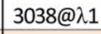 & 4556@入1 & 6834@入5 \\
\hline & $1 \times 4 \mathrm{Tx}$ & $900 @ \lambda 1$ & $1350 @ \lambda 1$ & 2025@入5 & 3038@入3 & $4556 @ \lambda 3$ & 6834@入2 \\
\hline & All-in-one & & & & & - & 6834@ג1 \\
\hline \multirow{3}{*}{ ONU 4} & $1 \times 1 \mathrm{Tx}$ & $900 @ \lambda 1$ & $1350 @ \lambda 1$ & 2025@入1 & 3038@入4 & 4556@入4 & $\begin{array}{c}502 @ \lambda 3 \\
6332 @ \lambda 4\end{array}$ \\
\hline & $1 \times 4 \mathrm{Tx}$ & $900 @ \lambda 1$ & $1350 @ \lambda 1$ & 2025@入2 & 3038@入5 & $4556 @ \lambda 2$ & 6834@ג1 \\
\hline & All-in-one & - & - & - & - & - & 6834@ג1 \\
\hline \multirow{3}{*}{ ONU 5} & 11 Tx & $900 @ \lambda 1$ & $1350 @ \lambda 2$ & 2025@入2 & 3038@入2 & $4556 @ \lambda 2$ & 6834@入2 \\
\hline & $1 \times 4 \mathrm{Tx}$ & $900 @ \lambda 1$ & $1350 @ \lambda 1$ & 2025@入1 & 3038@入1 & 4556@ג1 & $4 @ \lambda 1$ \\
\hline & All-in-one & - & - & - & - & - & $\begin{array}{l}3668 @ \lambda 1 \\
3166 @ \lambda 2\end{array}$ \\
\hline \multirow{3}{*}{ ONU 6} & $1 \times 1 \mathrm{Tx}$ & $900 @ \lambda 1$ & $1350 @ \lambda 1$ & 2025@入1 & 3038@入4 & $4556 @ \lambda 4$ & $\begin{array}{l}3166 @ \lambda 1 \\
3668 @ \lambda 4\end{array}$ \\
\hline & $1 \times 4 \mathrm{Tx}$ & $900 @ \lambda 1$ & $1350 @ \lambda 1$ & 2025@入1 & 3038@入1 & $4556 @ \lambda 1$ & 6834@ג1 \\
\hline & All-in-one & - & - & - & - & - & 6834@ג2 \\
\hline \multirow{3}{*}{ ONU 7} & $1 \times 1 \mathrm{Tx}$ & 900@入1 & $1350 @ \lambda 2$ & $025 @ \lambda 2$ & 3038@入1 & 4556@凡2 & 6834@入2 \\
\hline & $1 \times 4 \mathrm{Tx}$ & $900 @ \lambda 1$ & $@ \lambda 3$ & $\lambda 5$ & 338@入4 & 4556@入4 & $\begin{array}{c}502 @ \lambda 1 \\
3166 @ \lambda 4 \\
3166 @ \lambda 5\end{array}$ \\
\hline & All-in-one & - & - & - & - & - & 6834@入3 \\
\hline \multirow{3}{*}{ ONU 8} & $1 \times 1 \mathrm{Tx}$ & $900 @ \lambda 1$ & $1350 @ \lambda 2$ & $2025 @ \lambda 2$ & 3038@入3 & $4556 @ \lambda 2$ & 6834@入2 \\
\hline & $1 \times 4 \mathrm{Tx}$ & $900 @ \lambda 1$ & $1350 @ \lambda 2$ & 2025@入5 & 3038@入5 & $4556 @ \lambda 3$ & 6834@入5 \\
\hline & All-in-one & - & 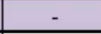 & - & - & - & 6834@ג4 \\
\hline \multirow{3}{*}{ ONU 9} & $1 \times 1 \mathrm{Tx}$ & $900 @ \lambda 1$ & $1350 @ \lambda 2$ & 2025@入2 & 3038@入2 & 4556@ᄉ2 & 6834@入2 \\
\hline & $4 \mathrm{Tx}$ & $900 @ \lambda 1$ & $1350 @ \lambda 1$ & 2025@入4 & 3038@入2 & 4556@入4 & 6834@ג1 \\
\hline & All-in-one & $\pi$ & - & - & - & - & 6834@入5 \\
\hline \multirow{3}{*}{ ONU 10} & $1 \times 1 \mathrm{Tx}$ & $900 @ \lambda 1$ & $1350 @ \lambda 1$ & 2025@入3 & 3038@入3 & 4556@入3 & $\begin{array}{l}4170 @ \lambda 2 \\
2664 @ \lambda 3\end{array}$ \\
\hline & $1 \times 4 \mathrm{Tx}$ & 90 & 13 & 20 & $@ \lambda 3$ & ఏर2 & \begin{tabular}{|c}
$502 @ \lambda 1$ \\
$3166 @ \lambda 2$ \\
$3166 @ \lambda 3$
\end{tabular} \\
\hline & \begin{tabular}{|l|l|} 
All-in-one \\
\end{tabular} & - & - & - & - & - & 6834@ג6 \\
\hline \multirow{3}{*}{$\begin{array}{c}\text { ONUs } 11 \\
\text { to } 16\end{array}$} & $1 \times 1 \mathrm{Tx}$ & $150 @ \lambda 1$ & $225 @ \lambda 1$ & 338@入1 & $506 @ \lambda 1$ & 759@入1 & $1139 @ \lambda 1$ \\
\hline & $1 \times 4 \mathrm{Tx}$ & $150 @ \lambda 1$ & $225 @ \lambda 1$ & 338@ג1 & $506 @ \lambda 1$ & 759@入1 & 1139@ג1 \\
\hline & All-in-one & - & - & - & - & - & 1139@ג1 \\
\hline
\end{tabular}

All values are in 'Mbps'. Allocated wavelength $i$ is denoted by '@ $\lambda i$ '. Bold wavelengths represent that a 40-Gbps line rate is being supported.

For each ONU and at each period, the table presents the wavelength and bandwidth allocated for cases: Base Case (adding single-wavelength transceivers, or ' $1 \mathrm{x} 1 \mathrm{Tx}$ '), adding 4-fixed-wavelength arrays of transceivers (named ' $1 \mathrm{x} 4 \mathrm{Tx}$ '), and all-in-one period calculation (referred as 'All-in-one').

TABLE III

ONUS UPGRADED With A 4-FIXED-WAVELENGTH ARRAY OF TRANSCEIVERS

\begin{tabular}{lcccccc}
\hline & $\begin{array}{c}\text { Period } \\
\mathbf{1}\end{array}$ & $\begin{array}{c}\text { Period } \\
\mathbf{2}\end{array}$ & $\begin{array}{c}\text { Period } \\
\mathbf{3}\end{array}$ & $\begin{array}{c}\text { Period } \\
\mathbf{4}\end{array}$ & $\begin{array}{c}\text { Period } \\
\mathbf{5}\end{array}$ & $\begin{array}{c}\text { Period } \\
\mathbf{6}\end{array}$ \\
\hline $\mathbf{1 x 4 T x}$ & - & 1,2 & 3,4, & 10 & - & - \\
$\lambda_{2-3-4-5}$ & & 7,8 & 9 & & & \\
\hline $\mathbf{1 x 4 T x + L R H}$ & - & 3,7, & 2,4, & 1 & - & - \\
$\lambda_{2-3-4-5}$ & & 8,10 & 6 & & & \\
$\lambda_{6-7-8-9}$ & - & - & - & - & 5 & $\begin{array}{c}1,4,6, \\
9,10\end{array}$ \\
\hline
\end{tabular}

ONUs indicated by their number ID at a certain period are being given a four-fixed-wavelength array of transceivers. Hence, such ONUs are supporting these four wavelengths from that period onwards.

In general, we expect that the longer our unique period evaluation is, the closer the result will be to the WDM-PON, where one wavelength is devoted to each single ONU.
TABLE IV

BANDWIDTH AND WAVELENGTH ALLOCATION DETAILS

\begin{tabular}{|c|c|c|c|c|c|c|c|}
\hline & \begin{tabular}{|c|} 
Cases \\
with LRH
\end{tabular} & Period 1 & | Period 2 & Period $3 \mid$ & Period 4 & Period 5 & Period 6 \\
\hline \multirow{2}{*}{ ONU 1} & $1 \times 1 \mathrm{Tx}$ & $900 @ \lambda 1$ & $1350 @ \lambda 1$ & 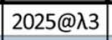 & $3038 @ \lambda 3$ & 4556@入1 & 6834@入8 \\
\hline & $1 \times 4 \mathrm{Tx}$ & $900 @ \lambda 1$ & 1350@入1 & 2025@入1 & 3038@入3 & 4556@入4 & 6834@ג7 \\
\hline \multirow{2}{*}{ ONU 2} & $1 \times 1 \mathrm{Tx}$ & $900 @ \lambda 1$ & 1350@入1 & 2025@入3 & 3038@入3 & 4556@入3 & $\begin{array}{l}2929 @ \lambda 3 \\
3905 @ \lambda>\end{array}$ \\
\hline & $1 \times 4 \mathrm{Tx}$ & $900 @ \lambda 1$ & $1350 @ \lambda 1$ & 2025@入5 & 3038@入4 & 4556@入3 & $\begin{array}{l}2734 @ \lambda 3 \\
4100 @ \lambda 4\end{array}$ \\
\hline \multirow[t]{2}{*}{ ONU 3} & $1 \times 1 \mathrm{Tx}$ & $900 @ \lambda 1$ & $1350 @ \lambda 1$ & 2025@入1 & 3038@入4 & 4556@入4 & $\begin{array}{l}5858 @ \lambda 4 \\
5857 @ \lambda 8\end{array}$ \\
\hline & $1 \times 4 \mathrm{Tx}$ & $900 @ \lambda 1$ & $350 @ \lambda 4$ & 2025@入3 & $3038 @ \lambda 2$ & 4556@ @ & 6834@入3 \\
\hline \multirow[t]{2}{*}{ ONU 4} & $1 \times 1 \mathrm{Tx}$ & $900 @ \lambda 1$ & $1350 @ \lambda 1$ & 2025@入1 & 3038@ג4 & 4556@入4 & $\begin{array}{l}3905 @ \lambda 4 \\
2929 @ \lambda 8\end{array}$ \\
\hline & $1 \times 4 \mathrm{Tx}$ & $900 @ \lambda 1$ & $1350 @ \lambda 1$ & 2025@入3 & $3038 @ \lambda 3$ & 4556@入5 & 6834@入5 \\
\hline \multirow[b]{2}{*}{ ONU 5} & $1 \times 1 \mathrm{Tx}$ & $900 @ \lambda 1$ & $1350 @ \wedge 2$ & 2025@入2 & $3038 @ \lambda 2$ & 4556@入2 & $\begin{array}{c}977 @ \lambda 2 \\
5857 @ \lambda 7\end{array}$ \\
\hline & $1 \times 4 \mathrm{Tx}$ & $900 @ \lambda 1$ & $1350 @ \lambda 1$ & 2025@ג1 & 3038@ג1 & 4556@入6 & $\begin{array}{l}2734 @ \lambda 6 \\
1366 @ \lambda 7 \\
2734 @ \lambda 8\end{array}$ \\
\hline \multirow[b]{2}{*}{ ONU 6} & $1 \times 1 \mathrm{Tx}$ & 900@入1 & $1350 @ \wedge 2$ & 2025@入2 & 3038@ג2 & 4556@入6 & $\begin{array}{l}\text { 1953@ג1 } \\
4881 @ \lambda 6\end{array}$ \\
\hline & $1 \times 4 \mathrm{Tx}$ & $900 @ \lambda 1$ & $1350 @ \lambda 1$ & 2025@入5 & 3038@ג5 & 4556@入4 & $\begin{array}{l}2732 @ \lambda 1 \\
2734 @ \lambda 2 \\
1368 @ \lambda 5\end{array}$ \\
\hline \multirow{2}{*}{ ONU 7} & $1 \times 1 \mathrm{Tx}$ & $900 @ \lambda 1$ & 1350@ג1 & 2025@ג1 & 3038@入1 & 4556@入5 & 6834@ג5 \\
\hline & $1 \times 4 \mathrm{Tx}$ & $900 @ \lambda 1$ & $1350 @ \lambda 5$ & 2025@ & $3038 @ \lambda 5$ & 4556@入2 & 6834@ג6 \\
\hline \multirow[t]{2}{*}{ ONU 8} & $1 \times 1 \mathrm{Tx}$ & $900 @ \lambda 1$ & 1350@入2 & 2025@ג2 & 3038@ג1 & 4556@入6 & $\begin{array}{l}1952 @ \lambda 2 \\
4882 @ \lambda 6\end{array}$ \\
\hline & $1 \times 4 \mathrm{Tx}$ & $900 @ \lambda 1$ & $1350 @ \lambda 2$ & 2025@入2 & $3038 @ \lambda 2$ & 4556@入2 & 6834@入2 \\
\hline \multirow{2}{*}{ ONU 9} & $1 \times 1 \mathrm{Tx}$ & $900 @ \lambda 1$ & $1350 @ \lambda 2$ & 2025@入2 & 3038@入2 & 4556@入2 & 6834@入2 \\
\hline & $1 \times 4 \mathrm{Tx}$ & $900 @ \lambda 1$ & $1350 @ \lambda 1$ & 2025@入1 & $3038 @ \lambda 1$ & 4556@入1 & 6834@ג8 \\
\hline \multirow[b]{2}{*}{ ONU 10} & $1 \times 1 \mathrm{Tx}$ & $900 @ \lambda 1$ & $1350 @ \lambda 1$ & 2025@入3 & $3038 @ \lambda 3$ & 4556@入3 & 6834@入3 \\
\hline & $1 \times 4 \mathrm{Tx}$ & 90 & $1350 @ \lambda 3$ & 2025@入3 & $\lambda 4$ & 455 & $\begin{array}{l}5468 @ \lambda 4 \\
1366 @ \lambda 5\end{array}$ \\
\hline \multirow{2}{*}{$\begin{array}{l}\text { ONUs } 11 \\
\text { to } 16\end{array}$} & $1 \times 1 \mathrm{Tx}$ & $150 @ \lambda 1$ & $225 @ \lambda 1$ & 338@入1 & $506 @ \lambda 1$ & 759@入1 & 1139@入1 \\
\hline & $1 \times 4 \mathrm{Tx}$ & $150 @ \lambda 1$ & 225@ג1 & $338 @ \lambda 1$ & $506 @ \lambda 1$ & 759@入1 & 1139@ג1 \\
\hline
\end{tabular}

All values are in 'Mbps'. Allocated wavelength $i$ is denoted by '@ $\lambda i$,. All wavelengths in the table run at a 10-Gbps line rate, over all the periods.

For each ONU and at each period, the table presents the wavelength and bandwidth allocated using the pricing policy with line-rate history (LRH) for two cases: adding single-wavelength transceivers (' $1 \mathrm{x} 1 \mathrm{Tx}$ '), adding 4-fixedwavelength arrays of transceivers (' $1 \mathrm{x} 4 \mathrm{Tx}$ ').

Adding Line-Rate History (LRH) to the ONU's Pricing Policy: We evaluate now the evolution of our PON case study using Policy 3, with single-wavelength transceivers ("1 $\times 1$ Tx + LRH") and multiple-wavelength transceiver arrays (" $1 \times 4 \mathrm{Tx}+\mathrm{LRH}$ "). Table IV shows the wavelength and bandwidth allocation details. We observe that, by adding line-rate history (LRH), bandwidth and wavelength allocations over ONUs differ significantly with respect to Pricing Policies 1 and 2. Table IV shows that no wavelength is upgraded to 40 Gbps and the PON supports eight wavelengths by period 6 (in both cases), regardless of the type of transceiver used.

When we include LRH awareness in the pricing policy for the ONU, changes from 10 to $40 \mathrm{Gbps}$ are avoided since for every ONU it implies a higher cost. This contrasts with Policies 1 and 2 in the price that is being given for an already-supported wavelength regardless of the line rate at the ONU. In LRH policy, we price the already-supported wavelength with a higher value when the wavelength is changing to a higher line rate. For some scenarios, it will be more expensive to upgrade the line rate (e.g., to $40 \mathrm{Gbps}$ ) than adding more wavelengths. In such cases, one can choose LRH policy. 


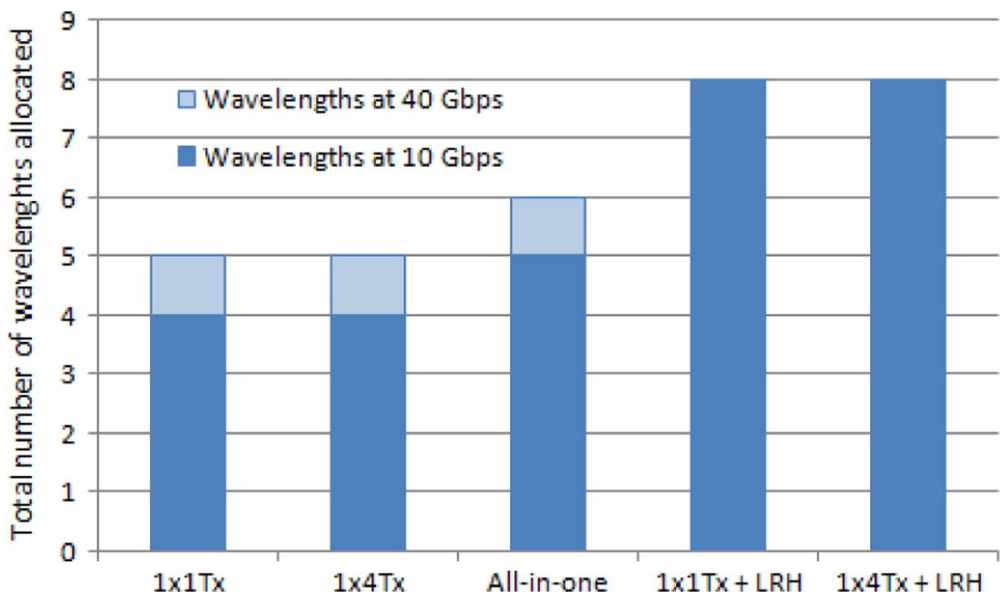

Fig. 3. Total number of wavelengths needed for different cases: Base Case (adding single-wavelength transceivers $1 \times 1$ Tx), adding four-fixed-wavelength arrays of transceivers $(1 \times 4 \mathrm{Tx})$, all-in-one period (at period 6), $1 \times 1 \mathrm{Tx}$ with line-rate history $(1 \times 1 \mathrm{Tx}+\mathrm{LRH})$ and $1 \times 4 \mathrm{Tx}+\mathrm{LRH}$.

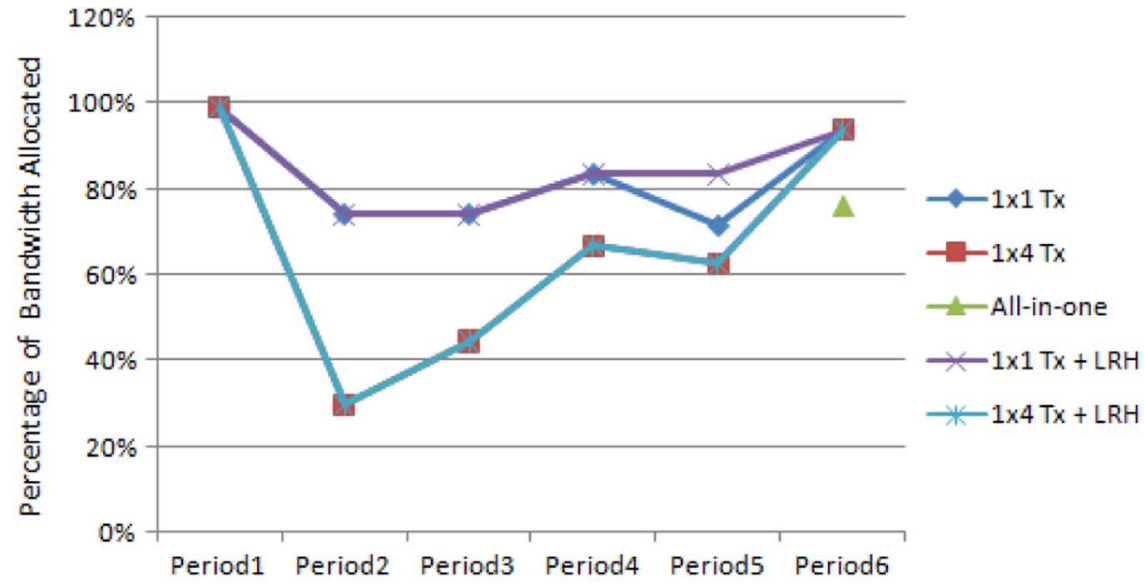

Fig. 4. Percentage of total bandwidth allocated to ONUs for different cases: $1 \times 1 \mathrm{Tx}, 1 \times 4 \mathrm{Tx}$, all-in-one (in period 6), $1 \times 1 \mathrm{Tx}+\mathrm{LRH}$ and $1 \times 4 \mathrm{Tx}+\mathrm{LRH}$.

It is interesting to note that for case " $1 \times 1+\mathrm{LRH}$," in Table IV, ONUs remain in supported wavelengths for as many periods as possible, e.g., ONU 10 changes from $\lambda_{1}$ to $\lambda_{3}$ in period 3 , and it remains on that wavelength for the rest of the periods. Also ONU 7 remains on $\lambda_{1}$ until period 4, and then it changes to and stays on $\lambda_{5}$. In general, our method tries to minimize disruptions while accomplishing a good bandwidth distribution according to the requirements.

In Table III (" $1 \times 4 \mathrm{Tx}+$ LRH"), we see how and when the arrays of transceivers are allocated to ONUs. After the capacity of the first group of wavelengths $\left(\lambda_{2}\right.$ to $\left.\lambda_{5}\right)$ is exhausted, a new group of wavelengths appears $\left(\lambda_{6}\right.$ to $\left.\lambda_{9}\right)$ in period 5. In period 5, only ONU 5 gets that new array of wavelengths. Note that ONU 5 was not supporting before the set of wavelength from $\lambda_{2}$ to $\lambda_{5}$. The same happens to ONU 9 in period 6. ONU 9 was not supporting the previous group of wavelengths $\left(\lambda_{2}\right.$ to $\left.\lambda_{5}\right)$, and it is being allocated a new array of transceivers (wavelengths from $\lambda_{6}$ to $\left.\lambda_{9}\right)$. For capacity reasons, other ONUs $(1,4,6$, and 10) support the two groups of wavelengths: $\lambda_{2}$ to $\lambda_{5}$ and $\lambda_{6}$ to $\lambda_{9}$ by period 6 . This example shows the continuity property of our method.

\section{B. Comparing All Cases}

Now, we compare all the cases: $1 \times 1 \mathrm{Tx}, 1 \times 4 \mathrm{Tx}, 1 \times 1 \mathrm{Tx}$ $+\mathrm{LRH}, 1 \times 4 \mathrm{Tx}+\mathrm{LRH}$, and all-in-one period.
Fig. 3 shows the total number of wavelengths for each case. In cases $(1 \times 1 \mathrm{Tx}$ and $1 \times 4 \mathrm{Tx})$ that require only five wavelengths, one of the wavelengths' line rates is $40 \mathrm{Gbps}$. On the other hand, some other cases $(1 \times 1 \mathrm{Tx}+\mathrm{LRH}$ and $1 \times 4 \mathrm{Tx}+\mathrm{LRH}$ ) require 8 wavelengths but all of them are running at $10 \mathrm{Gbps}$. This means that the total capacity in most of the cases (except for all-in-one period) is the same: $80 \mathrm{Gbps}$. As for the all-in-one-period approach, a total of $90 \mathrm{Gbps}$ was allocated to the system. The reason why our method chooses six wavelengths instead of five for the all-in-one case is related to the cost assigned in Policy 1. In the case of six wavelengths the relative cost is 17.3 , while with five wavelengths the cost is 17.6.

Fig. 4 compares all cases from bandwidth-usage point of view. The percentage of total bandwidth allocated to ONUs per period is shown. The highest bandwidth usage of the full PON capacity is in case " $1 \times 1 \mathrm{Tx}+$ LRH." Case " $1 \times 1 \mathrm{Tx}$ " has the second best capacity usage with the exception of the last two periods. This happens because there is a line-rate upgrade to 40 Gbps in period 5.

The plots for the cases using 4-wavelength transceiver arrays $(1 \times 4 \mathrm{Tx}$ and $1 \times 4 \mathrm{Tx}+\mathrm{LRH})$ overlap in Fig. 4 . They perform the same way because their increment is multiplied by four. So each increment will result many times in a bandwidth excess, depending on the traffic growth tendencies. 


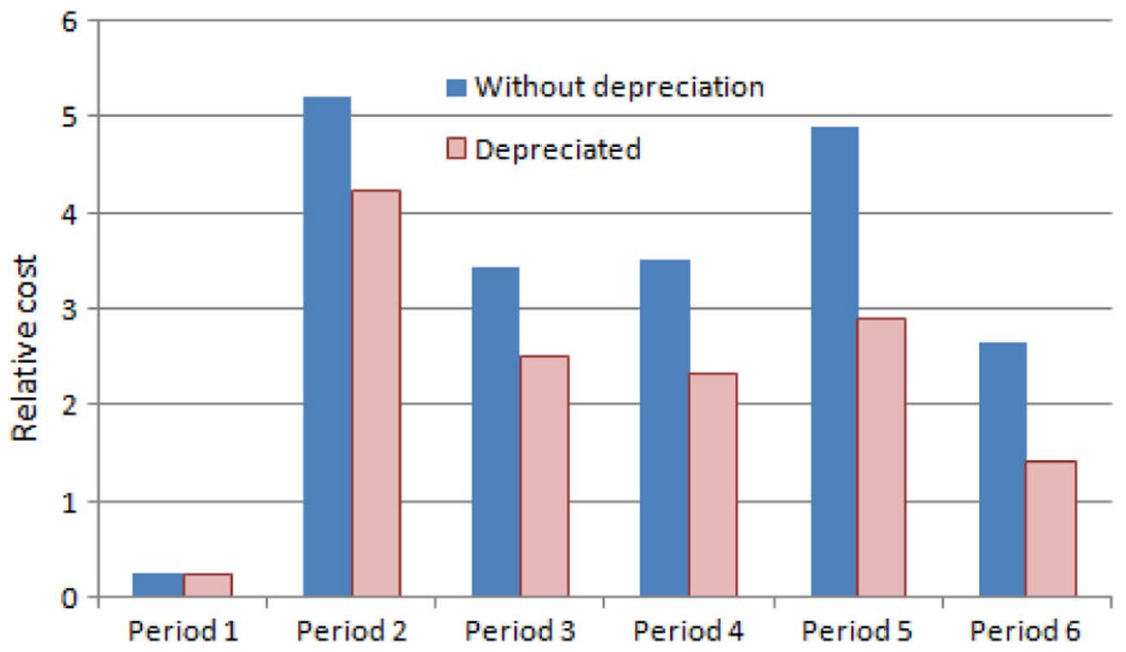

Fig. 5. Relative upgrade cost for Base Case $(1 \times 1 \mathrm{Tx})$, without depreciation and with $10 \%$ depreciation per period. Cost unit related to cost in dollars to add a new wavelength at $10 \mathrm{Gbps}$ to any ONU.

Finally, all-in-one-period case does not present a high capacity usage because it had from the first period an excess of $10 \mathrm{Gbps}$ in the total capacity compared to the other cases.

\section{Relative Cost Comparisons}

For cost comparison, we compare the Base Case with all-inone-period case and WDM-PON. In the last two cases, all the investment is done in the first period. We first calculate the relative cost per period (see Fig. 5) for our Base Case. We assume that cost unit is relative to the real cost in dollars required to add a new wavelength at $10 \mathrm{Gbps}$ to any ONU.

To calculate relative cost per period (without depreciation), we apply the upgrading policies presented in Section II-C.

Policy 1:

$$
\begin{aligned}
& \text { Relative Cost } \\
& =\text { No._of_new_As } @ 10 \text { Gbps_@OLT } * \mathrm{C}_{1} \\
& \text { + No._of_new_ } \lambda \mathrm{s} @ 40 \text { Gbps_@OLT } * \mathrm{C}_{2} \\
& + \text { No._of_old_ } \lambda_{\mathrm{s}} @ 10 \text { Gbps_@OLT } * \varepsilon
\end{aligned}
$$

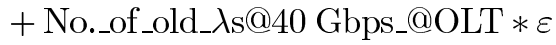

$$
\begin{aligned}
& \text { + No._of_old_ } \lambda \text { s_changing_from_10 } \\
& \times \text { Gbps_to_40 Gbps } *\left(\mathrm{C}_{2}+\omega\right) \\
& \text { + No._of_ONUs_using_new_ds@10 Gbps } * \mathrm{C}_{1} * 1 \\
& \text { + No._of_ONUs_using_new_ds@40 Gbps } * \mathrm{C}_{2} * 1 \\
& \text { + No._of_ONUs_using_old_ } \lambda \mathrm{s} @ 10 \mathrm{Gbps} * \varepsilon * \delta \\
& \text { + No._of_ONUs_using_old_ } \lambda \text { s@40 Gbps } * \varepsilon * \delta \\
& + \text { No._of_ONUs_using_ } \lambda \text { s_changing_from_10 } \\
& \times \text { Gbps_to_40 Gbps } *\left(\mathrm{C}_{2}+\omega\right) * \delta \text {. }
\end{aligned}
$$

For example, for period 5 (Table II) we can calculate the upgrade policies as follows (same order as previous equation): Relative Cost $=0 * 1+0 * 2.5+3 * 0.1+0 * 0.1+1 * 3$ $+0 * 1 * 1+0 * 2.5 * 1+11 * 0.1 * 0.1+0 * 0.1 * 0.1+5 * 3 * 0.1=4.91$.

Results in Fig. 5 include accumulated price depreciation of $10 \%$ per year. So, for period 5 , the relative cost with depreciation will be: $4.541 * 0.9^{5}=2.9$. In Fig. 5 , we see that the highest cost occurs in the second period. After that, the cost starts to decrease due to savings in wavelength and line-rate allocations, and due to depreciation. Period 5's relative high cost (especially considering no depreciation) is due to the investment on line-rate change required for $\lambda_{2}$.

Here, we compare our multiperiod study with an all-in-oneperiod run, and with WDM-PON. In WDM-PON, each ONU is allocated a different wavelength, e.g., we need 16 wavelengths for 16 ONUs. The cost will be: 16 transceivers at the OLT $* 1+$ 16 transceivers at the $\mathrm{ONU} * 1=32$.

Using Policy 1 also for all-in-one approach, total relative cost for the solution with 6 wavelengths is

Relative Cost $(6$ wavelengths $)=5 * 1+0 * 2.5+0 * 0.1+$ $0 * 0.1+1 * 3+6 * 1 * 1+0 * 2.5 * 1+0 * 0.1 * 0.1+0 *$ $0.1 * 0.1+11 * 3 * 0.1=17.3$.

Table V shows the total relative cost comparison among the three upgrade approaches. In particular, multiple-period cost is presented with depreciation and without depreciation. Table V shows that our multiple-step approach (with depreciation) to upgrade the PON has less total relative cost vs. the other two approaches (without depreciation in our multiperiod approach, the total relative cost is slightly higher than all-in-one-period approach). Having a longer traffic forecast (over several periods) to apply an all-in-one-period analysis may be more efficient if the prices depreciate little over time but considering $10 \%$ depreciation per year as in our study, we spend $27 \%$ more than in the multistep approach. WDM-PON performs poorest since it requires a different wavelength per ONU; so it is more expensive based on our pricing policies. Using WDM-PON upgrade approach means an important disruption for the entire PON since all ONUs will require a new wavelength, i.e., a new transceiver.

\section{Sensitivity Considerations}

We study the effect of the variation (sensitivity) of some parameters in the proposed method as reported in Table VI.

The value of $W_{k, j}$ affects the overall cost of the PON and the number of wavelengths that it can support. $Z_{k, i, j}$, on the other hand, limits how many wavelengths an ONU will support. If $Z_{k, i, j}$ is high, then the tendency is to upgrade to higher line 
TABLE V

TOtAl RELATIVE COST FOR DiFFERENT UPGRADING APPROACHES

\begin{tabular}{cc}
\hline \hline Upgrading Approach & Cost \\
\hline $\begin{array}{c}\text { Multiple periods 'Base Case' } \\
\text { depreciated }\end{array}$ & 13.6 \\
\hline $\begin{array}{c}\text { Multiple periods 'Base Case' } \\
\text { not depreciated }\end{array}$ & 20.0 \\
\hline All-in-one period & 17.3 \\
\hline WDMPON & 32 \\
\hline \hline
\end{tabular}

TABLE VI

SENSitivity LeVel to PARAmeter VALues

\begin{tabular}{ccc}
\hline \hline Parameter & Range & Sensitivity \\
\hline$W_{k, j}$ & $1-4$ & Very high \\
$Z_{k, i j}$ & $0.1-4$ & Very high \\
$\omega$ & $0-4$ & High \\
$\varepsilon$ & $10^{-3}-10^{-1}$ & Low \\
$\delta$ & $10^{-3}-10^{-1}$ & Low \\
$\alpha$ & $10^{-3}-10^{-6}$ & Medium \\
\hline \hline
\end{tabular}

rates. If $Z_{k, i, j}$ takes a low value, the ONUs may tend to support more wavelengths. Parameter $\omega$ directly affects the frequency we upgrade from a lower line rate to a higher one.

Constants $\varepsilon$ and $\delta$ have little impact as long as they remain at least one order of magnitude lower than the price given to add a new wavelength to the OLT or the ONU, respectively.

Finally, $\alpha$ has a medium level of sensitivity as it determines the cost to balance the bandwidth among all wavelengths. If $\alpha$ takes a high value, the method will give more priority to balancing the bandwidth than to minimizing the number of new wavelengths and line-rate upgrades. That would result in several ONUs supporting several wavelengths such that the traffic can be better balanced.

\section{CONCLUSION}

We proposed and evaluated a new multistep method to upgrade capacity of an existing PON. Given traffic demand forecast and initial PON settings, we devised a method for capacity upgrade with minimum cost and system disruption. The proposed solution is based on Mixed Integer Linear Programming and pricing policies that are executed over multiple periods of time.

We considered a WDM-TDM hybrid PON, where several ONUs may share in time one or more wavelengths. We showed the application of the steps of our method in a practical setting. The obtained results demonstrated multiple properties of this method, namely: minimization of the number of wavelengths in the PON, minimization of the number of channels supported by each ONU, minimization of disruptions per ONU and per period, minimization of capital expenses, history-aware upgrading process, load balancing over all the wavelength channels, and gradual capacity upgrade.

Different pricing policies were considered, namely: adding single-wavelength transceivers, adding multiple-wavelength transceiver arrays, and adding line-rate history in ONU's cost calculation. Multiwavelength transceiver arrays provide more flexibility, since an ONU may support multiple wavelengths at a time. However, the percentage of total network capacity usage is higher in using single-wavelength transceivers, especially if we consider historical information on wavelengths supported by each ONU and its respective line-rate.

For the same settings, we also applied our method in a unique period for a hybrid TDM-WDM PON (all-in-one period) and a WDM-PON (a different wavelength channel per ONU). The results showed that the multiperiod approach has the minimum total number of wavelengths and the minimum total relative cost. Multiple-periods approach allows gradual capacity upgrading and reduced capital expenses.

An open problem for future research is to design versatile pricing policies which can cope with most of the changes needed to add a new wavelength and to upgrade line rate, since in this study we consider the cost of adding transceivers as the main investment.

\section{REFERENCES}

[1] G. Kramer, Ethernet Passive Optical Networks. New York: McGrawHill, 2005.

[2] F. Effenberger, D. Cleary, O. Haran, G. Kramer, R. D. Li, M. Oron, and T. Pfeiffer, "An introduction to PON technologies," IEEE Commun. Mag., vol. 45, no. 3, pp. S17-S25, Mar. 2007.

[3] M. Hajduczenia, H. Da Silva, and P. Monteiro, "10 G EPON development process," in Proc. Int. Conf. Transparent Optical Networks (ICTON), Jul. 2007, vol. 1, pp. 276-282.

[4] , Standard IEEE 802.3av, 2009 [Online]. Available: http://www. ieee802.org/3/av/index.html/

[5] F. Effenberger and H. Lin, "Backward compatible coexistence of PON systems," in Proc. OFC/NFOEC Conf., Mar. 2009.

[6] J. Zhang, N. Ansari, Y. Luo, F. Effenberger, and F. Ye, "Next-generation PONs: A performance investigation of candidate architectures for next-generation access stage 1," IEEE Commun. Mag., vol. 46, no. 8, pp. S49-S57, Aug. 2009.

[7] F. Effenberger, H. Mukai, S. Park, and T. Pfeiffer, "Next-Generation PON-Part II: Candidate systems for next-generation PON," IEEE Commun. Mag., vol. 47, no. 11, pp. 50-57, Nov. 2009.

[8] A. Banerjee, Y. Park, F. Clarke, H. Song, S. Yang, G. Kramer, K. Kim, and B. Mukherjee, "Wavelength-division multiplexed passive optical network (WDM-PON) technologies for broadband access: A review [invited]," OSA J. Opt. Netw., vol. 4, no. 11, pp. 737-758, Nov. 2005.

[9] L. Kazovsky, W. Shaw, D. Gutierrez, N. Cheng, and S. Wong, "Nextgeneration optical access network," J. Lightwave Technol., vol. 25, no. 11, pp. 3428-3442, Nov. 2007.

[10] J. Lee, K. Choi, J. Moon, and C. Lee, "Seamless upgrades from a TDM-PON with a video overlay to a WDM-PON," J. Lightwave Technol., vol. 27, no. 15, pp. 3116-3123, 2009.

[11] B. Hesse, "Passive optical networking update, WDM-PON," IEEE Commun. Magazine, vol. 45, no. 3, pp. S6-S8, Mar. 2007.

[12] K. McCammon and S. W. Wong, "Experimental validation of an access evolution strategy: Smooth FTTP service migration path," in Proc. OFC/NFOEC 2007 Conf., Mar. 2007.

[13] J. Kani, F. Bourgard, A. Cui, A. Rafel, M. Campbell, R. Davey, and S. Rodrigues, "Next-generation PON-part I: Technology roadmap and general requirements," IEEE Commun. Mag., vol. 47, no. 11, pp. 43-49, Nov. 2009.

[14] , A. Shami, M. Maier, and C. Assi, Eds., Broadband Access Networks, Technologies and Deployments. New York: Springer, 2009.

[15] F. Clarke, S. Sarkar, and B. Mukherjee, "Simultaneous and interleaved polling: An upstream protocol for WDM-PON," in Proc., Optical Fiber Communication Conf. (OFC), 2006.

[16] M. McGarry, M. Reisslein, C. Colbourn, M. Maier, F. Aurzada, and M. Scheutzow, "Just-in-time scheduling for multichannel EPONs," J. Lightwave Technol., vol. 26, no. 10, May 2008.

[17] C. Meusburger and D. Schupke, "Optimizing the migration of channels with higher bit-rates," in Proc. OFC/NFOEC 2009 Conf., Mar. 2009, Post-Deadline Paper.

[18] R. G. Jeroslow, Logic-Based Decision Support: Mixed Integer Model Formulation. Amsterdam, The Netherlands: North-Holland, 1989. 


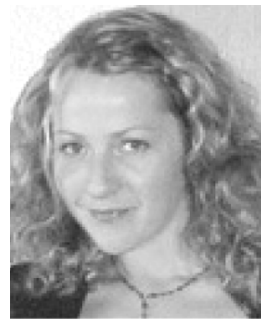

Marilet De Andrade (S'03) received the Electronic Engineering degree from Simon Bolivar University, Caracas, Venezuela, in 1998, and the M.S. degree in systems and communication networks from the Polytechnic University of Madrid, Madrid, Spain, in 2003. Currently, she is pursuing the Ph.D. degree in telematics engineering from the Polytechnic University of Catalonia (UPC), Barcelona, Spain. Her major field of study is broadband access networks and optical communications.

From 1998 to 2001, she served as Interconnections Engineer at Movistar Telefonica Venezuela (former Telcel Bellsouth). From 2003 to 2007, she held a Research Fellowship from the Spanish Ministry of Education, and worked for the Broadband Networks group at UPC. She was a Visiting Assistant Professor at UPC from 2007 to 2008. She spent one year (2009) in the Computer Science Department at University of California, Davis, as a Visiting Ph.D. Student. Currently, she is a Visiting Researcher in the Photonics and Microwave Engineering Laboratory, at Royal Institute of Technology (KTH), Sweden. Her research interests are PON evolution and resource management in broadband access networks.

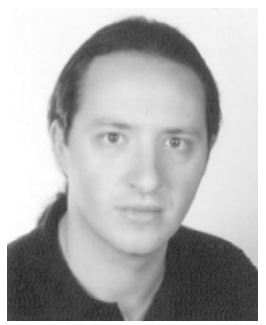

Massimo Tornatore (S'03-M'07) received the Laurea degree in telecommunications engineering in 2001 and a Ph.D. in information engineering in May 2006 from the Polytechnic University of di Milan, Italy.

He is currently Assistant Professor in the Department of Electronics and Informatics at Polytechnic University of di Milan. From 2007 to 2009, he was a post-doc researcher in the computer science department at the University of California, Davis, where he is still collaborating as a Visiting Researcher. He is co-author of more than 70 conference and journal papers and his research interests include design, energy efficiency, traffic grooming in optical networks and group communication security.

Dr. Tornatore is co-winner of the Optical Networking Symposium Best Paper Awards at the IEEE Globecom 2008, IEEE ANTS 2008 and IEEE ANTS (best poster) 2009 conferences.

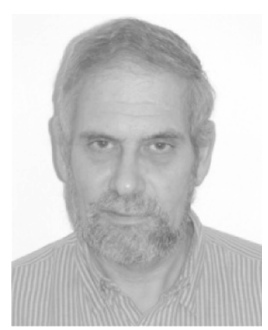

Sebastià Sallent (M'79) was born in Barcelona, Spain, on January 19, 1954. He received the M.Sc. (1979) and Ph.D. degrees (1988) degrees in telecommunications engineering from the Polytechnic University of Catalonia (UPC), Barcelona, Spain.

From 1979 to 1985 , he was with Philips Company, Barcelona. Currently, he is Full Professor at UPC, where he leads the Broadband Networks research group within the Department of Telematics Engineering. He is also the Director of the i2Cat Foundation, a non-profit organization for the promo-

tion of IT in Catalonia, Spain. He has participated in more than 15 research projects, funded by the EU (Federica, Phosphorus, NOVI, and Euro-NF, among others) the Spanish government, and private companies (Pais, Tarifa). He is co-author of more than 100 publications. He is co-author of Encyclopedia of Internet Technologies and Applications, Book Chapter Portugal, M. Freire and M. Pereira (editors), 2008, SIP: Advanced Media Integration (CRC Press, 2008), and An Adaptive Solution for Wireless LAN Distributed Power Saving Modes Computer Networks (Elsevier, 2009). His field of study is optical communications, Internet architectures and traffic measurement.

Prof. Sallent has been the President of Spanish Telematic Association, a TPC Member for several conferences, and has served as a reviewer for several conferences and journals.

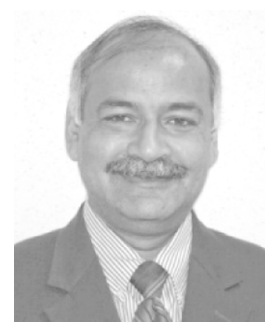

Seattle, in 1987

Dr. Mukherjee served as Technical Program Co-Chair of the Optical Fiber Communications (OFC) Conference 2009. He served as the Technical Program Chair of the IEEE INFOCOM'96 conference. He is Editor of Springer's Optical Networks Book Series. He serves or has served on the editorial boards of eight journals, most notable IEEE/ACM TRANSACTIONS ON NETWORKING and IEEE Network. He is Steering Committee Chair of the IEEE Advanced Networks and Telecom Systems (ANTS) Conference (the leading networking conference in India promoting industry-university interactions), and he served as General Co-Chair of ANTS in 2007 and 2008. Mukherjee is co-winner of the Optical Networking Symposium Best Paper Awards at the IEEE Globecom 2007 and IEEE Globecom 2008 conferences. To date, he has supervised to completion the $\mathrm{Ph} . \mathrm{D}$. Dissertations of 43 students, and he is currently supervising approximately $20 \mathrm{Ph} . \mathrm{D}$. students and research scholars. He is author of the textbook "Optical WDM Networks" published by Springer in January 2006. He served a five-year term as a Founding Member of the Board of Directors of IPLocks, Inc., a Silicon Valley startup company. He has served on the Technical Advisory Board of a number of startup companies in networking, most recently Teknovus, Intelligent Fiber Optic Systems, and LookAhead Decisions Inc. (LDI). 